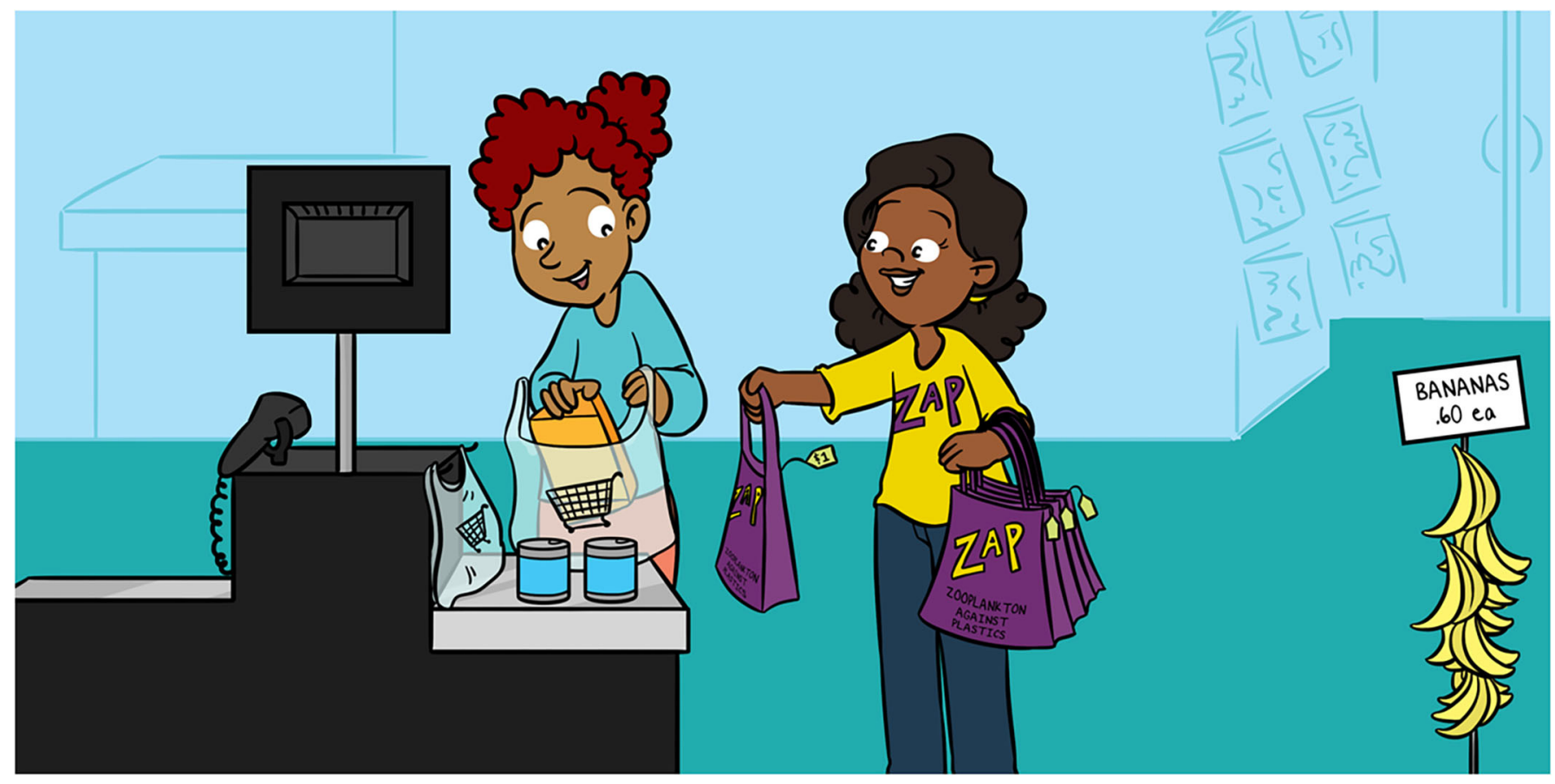

\title{
PLASTICS AND PLANKTON IN OUR SEAS
}

\section{Penelope K. Lindeque ${ }^{1 *}$, Zara L. R. Botterell ${ }^{1,2}$, Rachel L. Coppock $^{1}$ and Matthew Cole ${ }^{1}$ \\ ${ }^{1}$ Plymouth Marine Laboratory, Plymouth, United Kingdom \\ ${ }^{2}$ School of Life Sciences, University of Essex, Colchester, United Kingdom}

YOUNG REVIEWER:

MANUEL

AGE: 13
Plastic litter is found everywhere. Walk onto any beach around the world and you will almost certainly find plastic. The harm that large plastic litter can cause to marine animals is well-known; for example, you may have seen sad pictures of turtles eating plastic bags or seals tangled in discarded fishing nets. However, scientists are also concerned about microscopic-sized plastic that we do not normally see, and the problems these tiny plastic particles can cause to small marine animals called zooplankton. We focus on a group of zooplankton called copepods. These small-but-mighty crustaceans are amongst the most abundant animals on our planet, and they play a vital role in regulating Earth's climate. In this article, we will explain what happens when copepods encounter this microscopic plastic, why they eat plastic, and the impacts it has on their health and on the wider ecosystem. 


\section{MICROPLASTICS}

Very small pieces of plastic of various shapes, sizes, colours, and materials, $5 \mathrm{~mm}$ or smaller in size.

\section{ZOOPLANKTON}

Microscopic animals that float, swim, or drift with the ocean currents.

\section{MARINE FOOD WEB}

An interconnected network describing what organisms in a community eat and what eats them.

\section{COPEPODS}

A group of small crustaceans found in nearly every freshwater and seawater habitat. Copepods are food for many fish, so they are key components of marine food webs.

\section{THE MIX OF SMALL PLASTICS AND SMALL ANIMALS IN THE SEAS IS A BIG PROBLEM}

Humans have been making plastic for over 100 years and, globally, we currently produce over 380 million metric tonnes of plastic each year, the equivalent weight of approximately $76,000,000$ elephants! Plastic is an incredibly useful material; it is used to make things ranging from medical equipment to toys, cars, and mobile phones. However, almost half the plastic that is made is single-use plastic, which is designed to be used once and thrown away. For a material that is so durable, this really makes little sense. We are also not very good at recycling or disposing of plastic products when we have finished using them, so many plastics end up in our rivers, seas, and oceans. Scientists have found plastic litter everywhere, from the ocean surface to deep underwater trenches, and from deserted islands to the polar ice caps. Plastic litter pollutes the environment and is a threat to marine life, ecosystems, and possibly humans too (Figure 1).

Scientists are worried about the harm that small bits of plastic will cause when they are in our seas. These small plastics are called microplastics because they are microscopic in size $(<5 \mathrm{~mm})$. Microplastics include particles and fibres of various shapes, sizes, colours, and materials. Microplastics come from two main sources. Primary microplastics are manufactured to be of a microscopic size, and include small plastic pellets (known as nurdles or "mermaid's tears") that are the raw materials used to manufacture plastic goods, and the extremely small plastic beads used in toothpastes and in industry. Secondary microplastics are derived from the breakdown of larger plastic litter, through exposure to sun and by being scraped or worn away, or they are released into wastewater when we wash nylon or polyester clothing. Recent research has suggested there could be as many as 125 trillion pieces of microplastic floating in the oceans [1].

Our research on the risks that microplastics pose to marine life has concentrated on zooplankton, which are small animals found throughout our oceans that play critical roles in marine food webs and in regulating the Earth's climate. Considering there are so many microplastics and plankton in the sea, it led us to ask: "Do zooplankton eat microplastics and if so, is this a problem?"

\section{WHAT ARE COPEPODS?}

Copepods are small crustaceans, animals that are distantly related to crabs and shrimp. Copepods are amongst the most abundant animals on our planet. They are an important food source for many animals including fish, seabirds, and whales and are therefore a vital component of the marine food web. Copepods also play a very 
Figure 1

Plastic litter on a beach. If you look closely at this picture of a high-water line, you will see there is plastic litter mixed up with the natural material. It is plastic like this, although even smaller, that is a problem for zooplankton and other marine animals.

\section{CARBON CYCLE}

A combination of physical and biological processes that transfers carbon between Earth's biosphere (living things), hydrosphere (oceans, rivers, lakes), atmosphere (air), and geosphere

(rocks, seabed).

\section{PHYTOPLANKTON}

Microscopic plants that live in the ocean and make their own food from sunlight and carbon dioxide through photosynthesis.

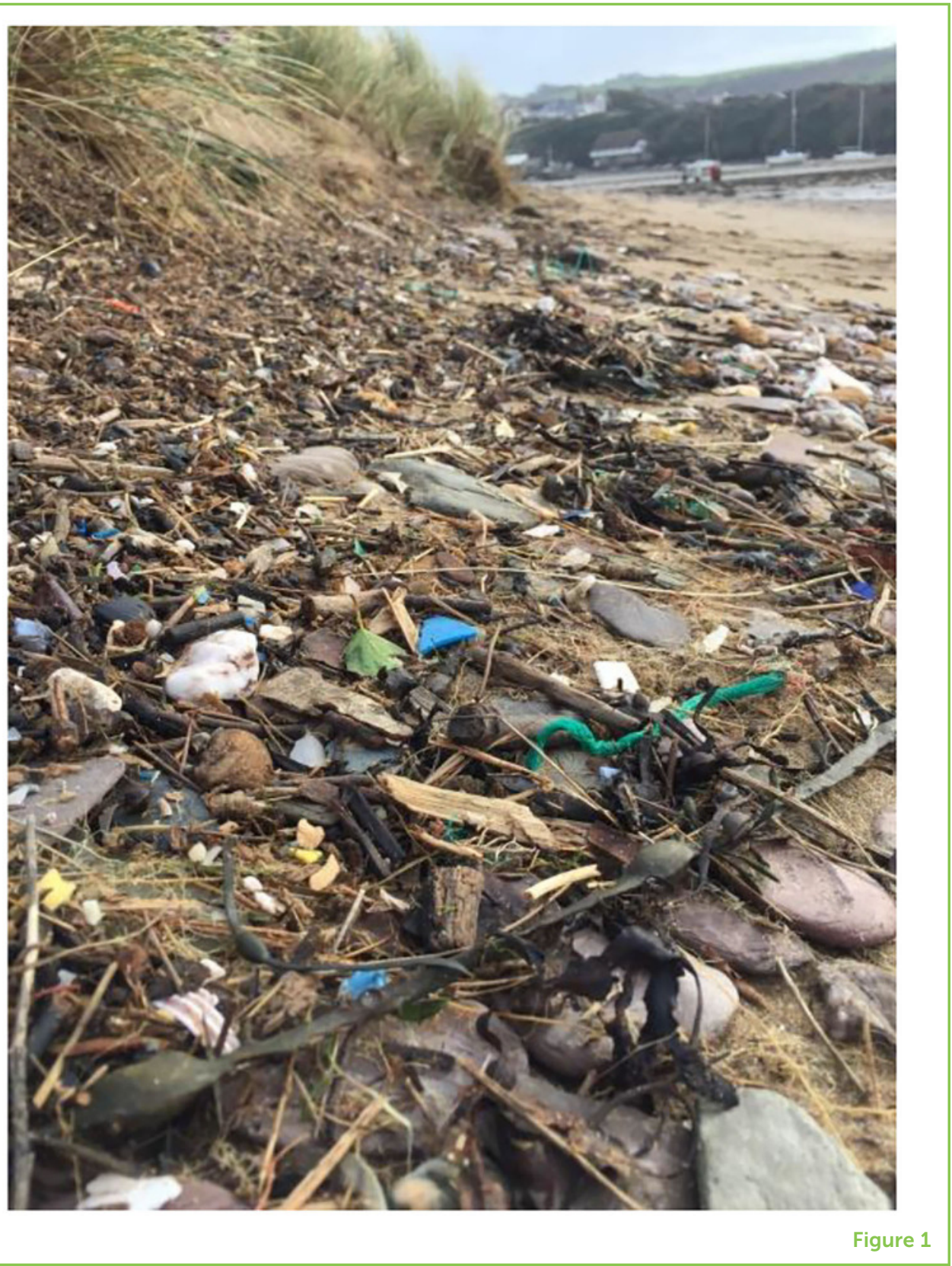

important role in the marine carbon cycle. This is where carbon, vital for all life, dissolves from the atmosphere $\left(\mathrm{CO}_{2}\right)$ in the oceans and mixes through the ocean layers by physical (i.e., ocean circulation) and biological processes. It is the biological processes within the marine carbon cycle that the copepods contribute to. Microscopic marine plants called phytoplankton absorb $\mathrm{CO}_{2}$ through photosynthesis, the copepods feed on the phytoplankton at the surface of the ocean at night and migrate to deeper water during the day to avoid being eaten by predators. In doing so copepods help to take carbon dioxide from the water's surface and store it in the deeper ocean through respiration (breathing) and the production of faecal pellets (poo). Microbes and other organisms use some of this carbon during respiration and some carbon gets buried in the seabed where it can form fossil deposits or 


\section{Figure 2}

Three different types of zooplankton: larva of a bivalve shellfish, a Porcellanid crab larva, and an adult copepod (Centropages typicus). Bright green and fluorescent microplastics of various sizes can be seen inside each of the animals.

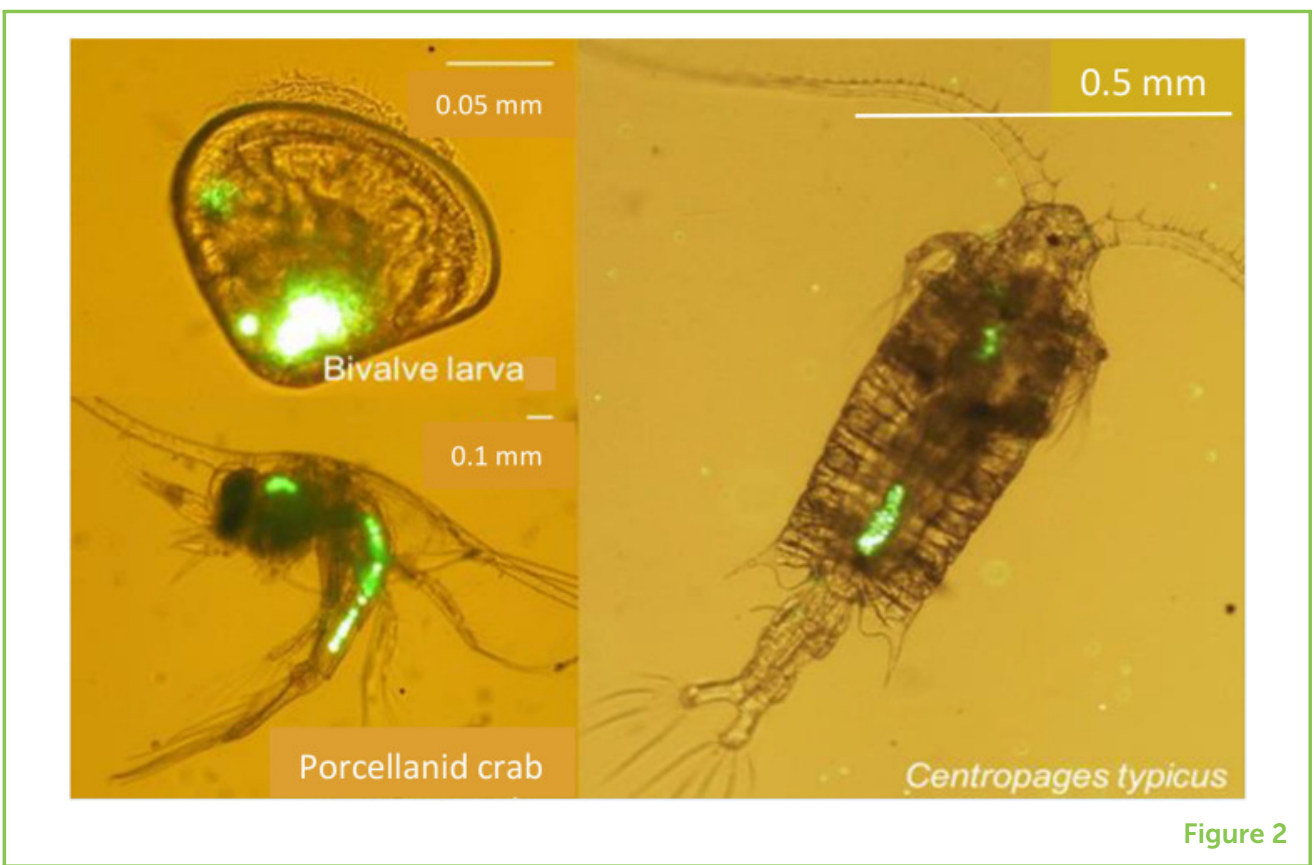

decompose and mix back to the surface. This is why we call copepods "small-but-mighty," by helping to transfer carbon from the sea surface to the ocean floor they help to sequester carbon into the deep ocean and therefore to regulate the Earth's climate.

\section{WHY WOULD COPEPODS EAT PLASTIC?}

Imagine eating plastic; it does not sound too tasty, right? Plastic is not normally on the menu for copepods, but when microplastics are mixed in with their food, the copepods can accidently eat them (Figure 2), especially since these microplastics often smell like their food. When microplastics enter the sea, bacteria and phytoplankton can attach to the surface of the plastic particles and grow there. Some species of phytoplankton produce a chemical called dimethyl sulphide (DMS). Do you get hungry when you smell freshly baked bread? That smell tells humans that there is food in the area. Similarly, DMS tells copepods that yummy phytoplankton is nearby. Humans can smell DMS too, only at much higher concentrations. If you have ever been to the beach and there is a really strong "smell of the sea," this is due to DMS.

In our research, we showed that copepods eat a lot more microplastics when the plastic particles are coated in DMS than when they are not. This means that copepods could eat more microplastics if the plastics mimic the scent of their normal food. But what exactly does eating microplastics do to copepods?

\section{WHAT HAPPENS IF COPEPODS EAT PLASTIC?}

If copepods eat really small amounts of plastic, it is unlikely to cause much of a problem. But if copepods keep eating plastic, they 
might stop eating as much actual food as they normally do. All animals need food to provide energy for movement and growth. We were concerned that microplastics could stop copepods from eating enough food, which might have an impact on their long-term health. We did some experiments in which we gave one group of copepods their normal food and a second group of copepods their normal food plus microplastics. We found that the copepods that got microplastics with food ate $40 \%$ less food than they usually would, and as a result these copepods produced smaller eggs that were less likely to hatch [2].

The chemicals in plastics may also pose a risk to marine wildlife. Plastics are full of chemicals that make them more colourful, resistant to fire, and easier to shape into various products. Sunlight can cause plastic litter to become brittle, allowing these chemicals to escape. Animals that eat plastics can be affected by these chemicals. For example, we found that a chemical called benzophenone, which protects plastics from breaking down in strong sunlight, may be released by nylon plastics. This chemical caused copepods to develop more quickly than normal [3].

\section{WHAT IS THE IMPACT OF MICROPLASTICS ON THE MARINE CARBON CYCLE?}

Even though copepods are very small, remember that these animals and their poo play a really important role in the marine carbon cycle. We found that, after eating microplastics, copepods poop these plastics out in their faecal pellets. The pellets carry the plastic down towards the seabed and to the hungry animals waiting there. We were curious to know whether these microplastics might affect the carbon cycle.

We carried out some experiments in which we fed copepods plastics, collected their poo, and then timed how quickly the poo sank! We found that, if the plastic that was eaten can float in seawater, the faecal pellets sank more slowly [4]. In the ocean, slow-sinking faecal pellets will spend more time in the warmer surface waters and will degrade faster, releasing the microplastics back into the water and preventing the movement of carbon into deeper water. When copepods eat microplastics that are denser than seawater, their faecal pellets sink much faster and reach the seabed quicker (Figure 3) [5]. Many animals living on or in the seabed rely on zooplankton poo and decaying carcasses for their food; if this poo contains microplastics, the animals on the seabed will also eat the plastics. Our latest research has shown that animals that live at the bottom of the sea can mix microplastic into the sediment as they feed and move, contributing to the permanent burial of microplastics in our oceans. Some scientists think plastics may be locked within sediments, without degrading, for hundreds or 


\section{Figure 3}

(A) A copepod eats microplastic at the surface of the ocean.

(B) Some of the plastic will be pooped out in the copepod's faecal pellets. (C) Faecal pellets sink,

transporting carbon to the depths of the ocean. (D,E) Faecal pellets containing microplastics may take longer to sink and may be eaten by different organisms or might break up and release the plastic back into the water [4].

\section{FOSSIL RECORD}

History of life as documented by fossils.

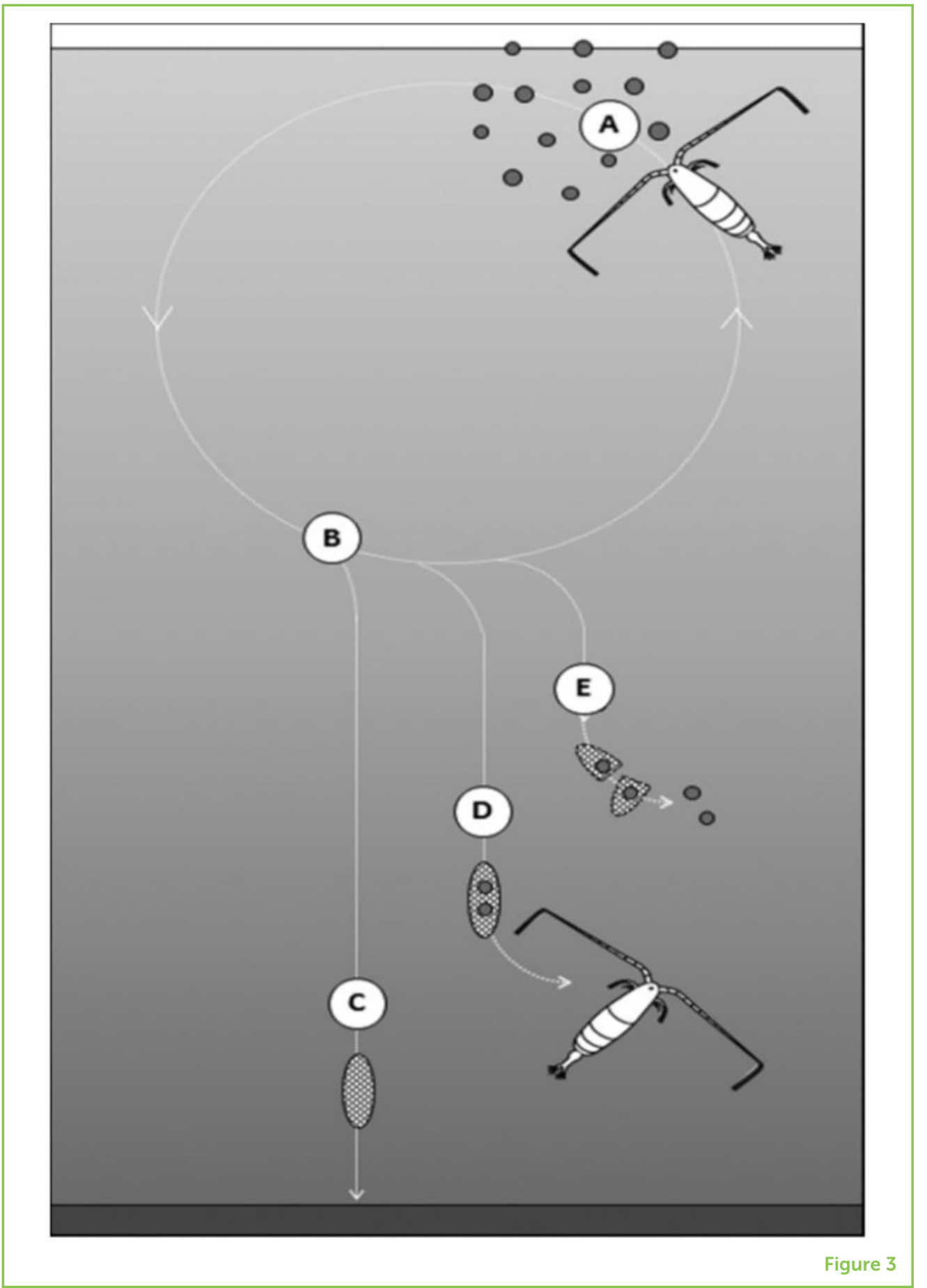

even thousands of years. Microplastics could end up becoming part of the fossil record.

\section{HOW CAN EVERYONE HELP?}

Our research is helping people understand the risks and concerns posed by microplastic pollution in our oceans. We have provided scientific evidence to politicians, which has led to charges for single-use plastic bags at the supermarket and the banning of 
microbeads in face scrubs and toothpaste, which get washed down the sink and eventually end up in the ocean. We are also exploring whether mussels and seagrasses can be used as part of a nature-based solution to help stop the flow of microplastic from their sources into the sea.

As for non-scientists, every little bit helps! There are over 7 billion people on this planet, so if everyone used just one less plastic bottle, think of how much less plastic would be used every single day. Reducing usage of single-use plastics wherever possible is a great place to start, from bringing your own reusable water bottle and shopping bags, or perhaps choosing food with less packaging at the supermarket. Next time you take a walk on the beach or in your local area, consider doing a 2-min litter pick-up. This will help prevent plastic pollution from entering the sea. Working together, scientists and non-scientists can help to reduce the threat of microplastic pollution. These efforts will benefit the environment and improve the lives of copepods and many other living things, including humans!

\section{REFERENCES}

1. Lindeque, P. K., Cole, M., Coppock, R. L., Lewis, C. N., Miller, R. Z., Wilson-McNeal, A. J. R., et al. 2020. Are we underestimating microplastic abundance in the marine environment? A comparison of microplastic capture with nets of different mesh-size. Environ. Pollut. 265(Pt. A):114721. doi: 10.1016/ j.envpol.2020.114721

2. Cole, M., Lindeque, P., Fileman, E., Halsband, C., and Galloway, T. S. 2015. The impact of polystyrene microplastics on feeding, function and fecundity in the marine copepod Calanus helgolandicus. Environ. Sci. Technol.

49:1130-7. doi: 10.1021/ES504525U

3. Cole, M., Coppock, R., Lindeque, P. K., Altin, D., Reed, S., Pond, D. W., et al. 2019. Effects of nylon microplastic on feeding, lipid accumulation, and moulting in a coldwater copepod. Environ. Sci. Technol.

53:7075-82. doi: 10.1021/acs.est.9b01853

4. Cole, M., Lindeque, P. K., Fileman, E., Clark, J., Lewis, C., Halsband, C., et al. 2016. Microplastics alter the properties and sinking rates of zooplankton faecal pellets. Environ. Sci. Technol. 50:3239-46. doi: 10.1016/j.scitotenv.2019.06.009

5. Coppock, R. L., Galloway, T. S., Cole, M., Fileman, E. S., Queirós, A. M., and Lindeque, P. K. 2019. Microplastics alter feeding selectivity and faecal density in the copepod, Calanus helgolandicus. Sci. Tot. Environ. 687:780-9. doi: 10.1016/j.scitotenv.2019.06.009

SUBMITTED: 29 July 2020; ACCEPTED: 02 September 2021; PUBLISHED ONLINE: 06 October 2021.

EDITED BY: Hervé Claustre, Centre National de la Recherche Scientifique (CNRS), France 


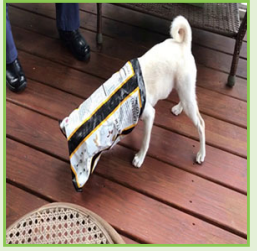

CITATION: Lindeque PK, Botterell ZLR, Coppock RL and Cole M (2021) Plastics and Plankton in Our Seas. Front. Young Minds 9:588638. doi: 10.3389/frym.2021.588638

CONFLICT OF INTEREST: The authors declare that the research was conducted in the absence of any commercial or financial relationships that could be construed as a potential conflict of interest.

COPYRIGHT @ 2021 Lindeque, Botterell, Coppock and Cole. This is an open-access article distributed under the terms of the Creative Commons Attribution License (CC BY). The use, distribution or reproduction in other forums is permitted, provided the original author(s) and the copyright owner(s) are credited and that the original publication in this journal is cited, in accordance with accepted academic practice. No use, distribution or reproduction is permitted which does not comply with these terms.

\section{YOUNG REVIEWER}

\section{MANUEL, AGE: 13}

Hello! My name is Manuel, and I am an aspiring teenage boy. I was born in the U.S. of A and my parents are South American. I have always loved animals, so when I grow up, I hope to be a bio-engineer or a marine biologist. My hobbies include playing video games, reading and listening to true crime podcasts. I have always loved the unknown and mysterious, so I always try to learn more!

\section{AUTHORS}
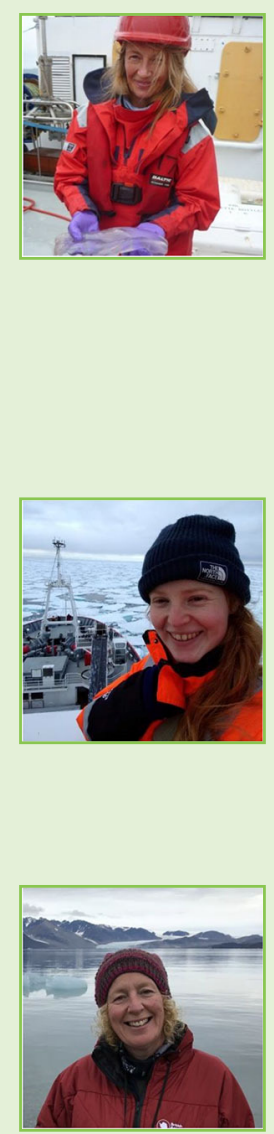

\section{PENELOPE K. LINDEQUE}

I am a marine biologist at the Plymouth Marine Laboratory. My work focuses on zooplankton, small animals at the base of the marine food web. I develop and use molecular techniques to identify zooplankton, investigate what they eat and what eats them, and to look at their responses to environmental stress and pollution. I am also interested in the source, distribution, and impact of microplastics and microdebris on marine animals, including zooplankton. When I am not working, I love being near, on, or in the sea, rowing, paddle-boarding, or playing with my family and dogs. *pkw@pml.ac.uk

\section{ZARA L. R. BOTTERELL}

I am a marine biologist based at Plymouth Marine Laboratory. My research investigates why zooplankton eat microplastics, including what factors may affect their ingestion, such as size, shape, or smell. I am also very interested in what zooplankton currently eat in our oceans and how this may affect the wider ecosystem. My recent research focuses on microplastic ingestion by zooplankton in the Arctic seas.

\section{RACHEL L. COPPOCK}

As a marine ecologist at Plymouth Marine Laboratory, I am investigating the risks microplastics pose to marine life and the ecosystems they live in, and I help explore nature-based solutions to marine microplastic pollution. I am interested in the 


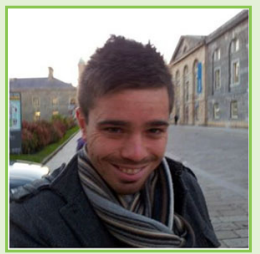

impact of microplastic pollution in Arctic seas, which are warming faster than anywhere else on the planet. I have also developed a method to extract microplastics from marine sediments, to help figure out how much plastic is in the seabed and to understand the ultimate fate of microplastic litter around our coasts.

\section{MATTHEW COLE}

I am a marine ecologist at Plymouth Marine Laboratory. Over the past 10 years, I have been investigating how marine life interacts with microplastic debris. My research was the first to reveal that microplastics can be eaten by marine zooplankton. In recent years, our research group has been exploring how microplastics can have a negative impact on the health of zooplankton. Currently, I am exploring whether we could harness the power of mussels to help remove microplastics from estuaries! 